\title{
MATERNAL DISEASES AND RISK OF ISOLATED EAR ABNORMALITIES IN THEIR CHILDREN
}

\author{
László Paput ${ }^{1}$, Andrew E. Czeizel ${ }^{2}$, Ferenc Bánhidy ${ }^{3}$ \\ ${ }^{1}$ Department of Oto-Rhino-Laryngologic and Head/Neck Surgical Department, National Center for Healthcare Audit and Improvement, \\ Budapest, Hungary \\ ${ }^{2}$ Foundation for the Community Control of Hereditary Diseases, Budapest, Hungary \\ ${ }^{3}$ Second Department of Obstetrics and Gynecology, Semmelweis University, School of Medicine, Budapest, Hungary
}

\section{SUMMARY}

The objective of the study was to estimate the possible association of maternal diseases with the risk of isolated ear congenital abnormalities (IECA) including mainly microtia and anotia in their children. Incidence of acute and prevalence of chronic maternal diseases in the mothers with IECA and in the mothers of their matched controls and all controls without any defects, in addition in the mothers of malformed controls with other isolated defects was compared in the population-based large dataset of the Hungarian Case-Control Surveillance of Congenital Abnormalities. Of 354 cases with IECA, 32 had mothers with high fever related influenza-common cold during the critical period of IECA and it resulted in a higher risk of IECA in their live-born infants (adjusted OR with $95 \% \mathrm{Cl}$ : 4.3, 1.9-7.4) compared with their matched controls. However, the early and effective antifever treatment in these pregnant women prevented them from the IECA. In addition there was an association of maternal otitis media with higher risk of complex defects of middle and external ears (OR with $95 \% \mathrm{Cl}: 5.2,1.6-28.3$ ), however, this association was based on 4 cases only. In conclusion high fever related influenza-common cold with secondary complications may play a role in the origin of IECA, but is preventable with the early and effective antifever treatment of these pregnant women.

Key words: isolated ear abnormalities, microtia, anotia, pregnancy, influenza-common cold, population-based case-control study

Address for correspondence: L. Paput, 1062 Budapest, Podmaniczky utca 109-111, Hungary. E-mail: barabas.ev@gmail.com

\section{INTRODUCTION}

The structural birth defects, i.e. congenital abnormalities (CAs) of external ears are visible, therefore easily diagnosed in the newborn infants by routine inspection. Among them, microtia is more, while anotia is less frequent. Microtia and anotia comprise a spectrum of the same developmental field defect $(1,2)$. However, microtia/anotia may associate with aural atresia/stenosis and middle ear defects (3), thus middle ear defect and microtia/ anotia together represent the complex CA of ear. These ear CAs are evaluated in this study.

However, at the evaluation of patients with ear CA, their isolated and multiple (the so-called syndromic) manifestation should be differentiated because of their different clinical importance and etiology. The etiology of isolated ear CAs (IECA), including microtia/anotia, is less known (4-6), thus the aim of our population-based case-control study is to estimate the possible association of maternal diseases with the risk of IECA in the large data set of the Hungarian Case-Control Surveillance of Congenital Abnormalities (HCCSCA) (7).

\section{MATERIALS AND METHODS}

The objective of the HCCSCA is to compare the exposures, e.g. maternal diseases, in pregnant women of cases and controls.

\section{Cases and Controls}

Cases with CA were selected from the Hungarian Congenital Abnormality Registry (HCAR) (8) for the HCCSCA. Reporting of cases with CA is mandatory for physicians from the birth until the first birthday to the HCAR and most CAs are reported by obstetricians (in Hungary practically all deliveries take place in inpatient obstetric clinics and birth attendants are obstetricians) or paediatricians (working at neonatal units of inpatient obstetric clinics as well as of various general and special surgical, oto-rhino-laryngologic, etc. inpatient and outpatient paediatric clinics). Autopsy was obligatory for all infant deaths and was usually (about $80 \%$ ) performed in stillborn fetuses during the study period. In case of defects identification in stillborn fetuses or infant deaths, pathologists sent a copy of the autopsy report to the HCAR. Since 1984, fetal defects have been diagnosed by prenatal diagnostic centres with or without elective termination of pregnancy have also been notified to the HCAR.

CAs were differentiated into two main categories: isolated (only one organ is affected) and multiple (concurrence of two or more CAs in the same person affecting at least two different organ systems) CAs (9). Minor anomalies or morphological variants without serious medical or cosmetic consequences are recorded in the HCAR but these cases are excluded from the estimation of different $\mathrm{CA}$ rates.

The total (birth + fetal) prevalence of cases with CA diagnosed from the second trimester of pregnancy through the age of one was 35 per 1,000 informative offsprings (live-born infants, 
stillborn fetuses and electively terminated malformed fetuses) in the HCAR, 1980-1996 (8), and about 90\% of major CAs were recorded in the HCAR during the 17 years of the study period (10).

The diagnosis of IECA was checked in the HCAR and modified if necessary by two steps: 1) if cases with unspecified ear CAs were reported to the HCAR, an extra effort was made by the assistant of the HCAR to contact the medical doctors who notified these cases in order to specify the diagnosis, 2) for the request of parents the co-workers of the HCAR organized the so-called parental meetings for the families of cases with ear CAs in the institute of the HCAR in 1988 and 1996. These meetings had three aims: (i) providing information for parents regarding the ear CAs and replies to their questions, (ii) exchanging experience among parents and (iii) the examination of these cases by experts. Thus, we were able to examine personally about one-third of cases with IACA.

However, cases with IECA in the study were evaluated in the dataset of the HCCSCA (7).

Cases with CA were selected from the HCAR while controls were defined as newborn infants without $\mathrm{CA}$ and they were identified in the National Birth Registry of the Central Statistical Office on the basis of list of cases in the HCCSCA. In general, two controls were matched with every case according to sex, birth week in the year when cases were born and district of parents' residence. The name and address of controls' mothers were also given to the co-workers of the HCCSCA. These controls were used in two different approaches: (I) matched controls of cases with IECA studied, (II) all controls because their large number helps us to improve the generalisibility of the results.

In addition, there was a third control group including (III) malformed controls selected from the HCAR, they were live-born cases with isolated CA but without cases with IECA.

\section{Collection of Exposure and Confounder Data \\ 1. Medically Recorded Prospective Data}

Mothers of cases and controls were asked in a mailed explanatory letter to send us the prenatal maternity logbook and discharge summaries of their deliveries and, in addition, recent medical documents regarding their child's CA. Prenatal care was mandatory for pregnant women in Hungary (if somebody did not visit prenatal care, she did not get maternity grant and leave), thus nearly $100 \%$ of pregnant women visited prenatal care, on average seven times. The first visit was between 6 th and 12 th gestational weeks. The task of obstetricians was to record all pregnancy complications, maternal diseases and related drug prescriptions in the prenatal maternity logbook.

\section{Retrospective Self-reported Maternal Information}

A structured questionnaire together with a list of diseases and drugs, and a printed informed consent were also mailed to the mothers immediately after the selection of cases and controls. In order to standardise the answers, mothers were asked to read the enclosed list of diseases and medications, as a memory, aid before replying. Mothers were asked to give a signature for informed consent which authorized us to record the name and address of their children in the HCCSCA.

The period between birth or elective termination of pregnancy and return of "information package" (questionnaire, logbook, informed consent, etc.) in our prepaid envelope was 3.5+1.2 and $5.2+2.9$ months for cases and controls, respectively.

\section{Supplementary Data Collection}

Regional nurses were asked to visit all non-respondent mothers of cases (including malformed controls) at home, to help mothers to fill-in the same questionnaire, to evaluate available medical documents, in addition to obtain data regarding lifestyle (smoking, drinking, and illicit drug use) and some important symptoms (e.g. high fever) of diseases during pregnancy through a personal mothers' interview and their close relatives living together. The data of lifestyle were collected only in these subsamples due to the unreliability of retrospective maternal information (11). Co-workers of the HCCSCA visited only 200 non-respondent and 600 respondent control mothers in two validation studies $(12,13)$, as the ethic committee considered that this follow-up would be disturbing to the parents of healthy children. The same method was used in these control mothers as in non-respondent case mothers.

The diagnosis of IECA was checked in the HCCSCA and modified if necessary by two steps: (i) the recent medical examinations of cases after postnatal months helped us to achieve more accurate diagnoses and (ii) an expert examination was suggested by the principal investigator of the study in about one-third of cases with complex ear CA or with severe IECA diagnosis in our institute or visited at home. At the classification of IECA (14-16), 4 types were differentiated:

Mild microtia: the structure of smaller external ear is moderately anomalous. The auricle can be hook-, S- or question mark shaped in appearance with a more or less irregular mass of cartilage, but the external auditory meatus is usually present, but frequently had stenosis.

Severe microtia: external ear is rudimentary and auricle does not include cartilage, only soft tissue and there is no external auditory meatus.

Anotia: all external ear structures are absent, thus there is no external auditory meatus/canal. Skin of the cheek passes smoothly over the aural area without definite elevation or depression.

Complex ear CA: anotia/microtia associates with middle ear CAs and anotia/microtia, or anotia occurs in one side while microtia in other side.

Among exposures, maternal diseases were evaluated in the study: chronic diseases were analysed on the basis of prenatal maternity logbooks and/or other medical records, while the source of acute maternal diseases was both medical records and the questionnaire.

The timing of exposures: the gestational age was calculated from the first day of the last menstrual period. The auricle is formed from the first and second branchial arches by a series of auricular hillocks that surround the first pharyngeal groove during the sixth postconceptional week (17), therefore the critical period of microtia/anotia is in the eighth gestational week. Thus, the second gestational month is the most sensitive time window of potential exposures, but because of the inaccuracy of this time calculation (both in the gestational age and exposure time) the third gestational month was also considered.

Among potential confounding factors, maternal age, birth order, marital and employment status as indicator of socioeconomic status because it correlated well with the level of education and 
income (18), related drug treatments, and the use of pregnancy supplements, mainly folic acid (19) were considered.

Finally necessary data were collected for $96.3 \%$ of cases ( $84.4 \%$ from reply, $11.9 \%$ from visit) and for $83.0 \%$ of population controls ( $81.3 \%$ from reply, $1.7 \%$ from visit). Informed consent was signed and returned by $98.4 \%$ of mothers.

The procedure of data collection was changed in 1997 because regional nurses visited and questioned all cases and controls, and the recent data had not been validated at the time of this analysis, thus only the data set of 17 years between 1980 and 1996 has been evaluated.

\section{Statistical Analysis}

The software package SAS version 8.02 (SAS Institute Inc., Cary, North Caroline, USA) was used. First, frequency tables were made for the main maternal variables in order to describe the study groups. Second, the characteristics of pregnant women with IECA and controls were compared using Student t-test for quantitative and chi-square statistics or odds ratios (OR) with $95 \%$ confidence interval $(\mathrm{CI})$ for categorical variables. Third, the incidence of acute disease groups and the prevalence of chronic diseases during the study pregnancy of mothers of cases with IECA and mothers of matched controls was compared using conditional logistic regression model, while at the comparison of case mothers and the mothers of all controls or malformed controls ordinary logistic regression model was used. At the calculation of adjusted OR with 95\% CI maternal age and employment status, in addition birth order and drug treatments were considered.

\section{RESULTS}

All IECA were diagnosed in live-born infants, these cases with different IECA types are shown in Table 1. The group of "others" included 20 cases, 18 were personally examined. Seven cases had anotia/microtia with middle ear CAs, 12 cases were affected with anotia in one side and microtia in other side, and one case was affected with polyotia and microtia.

There was a slight male excess among cases with IECA with an obvious predominance of unilateral manifestation of anotia/ microtia, though the cases of "others" were exceptional.

The maternal demographic data in the groups of cases with IECA and different controls are shown in Table 2. The number of all controls was 38,151 and represented $1.8 \%$ of all Hungarian newborns. The mean maternal age in the case group of IECA did not differ significantly from the figures of control mothers. The mean birth order was higher in the mothers of cases with IECA compared to matched controls and all controls; however, there was no difference in the mean birth order between cases with IECA and malformed controls.

Table 3 summarizes the data reflecting the socio-economic status of mothers in the different study groups. There was no significant difference in the marital status of mothers in the study groups. The distribution of employment status was different between case mothers and matched or all control mothers, but not between case and malformed control mothers. These differences reflect the lower proportion of the two groups of high socioeconomic status, i.e. professional and managerial employment in the mothers of cases with IECA and malformed controls. The lowest proportion of professional women was found in the group of cases with IECA.

Proportion of smokers and drinkers did not show any significant difference among the study groups.

The incidence of acute maternal disease groups during the study, pregnancy in the mothers of cases with IECA was compared to the figures of different control mothers (Table 4). The incidence of influenza-common cold with secondary complications (later only influenza-common cold is mentioned) was significantly higher in the mothers of cases with IECA than in the mothers of their matched controls. The incidence of respiratory system's diseases was significantly higher in all control and malformed control mothers. The incidence of urinary tract's diseases in case mothers was only higher than in all control mothers. In the group of other acute diseases, otitis media occurred more frequently in the group of case mothers than in control mothers.

The critical period of IECA is in the second and/or third gestational months thus the incidence of influenza-common cold, respiratory system and urinary tract's diseases were evaluated separately only during this time window (Table 4). Only high fever related influenza-common cold associated with the higher risk of IECA.

Of 22,843 cases, $5,155(22.6 \%)$, while of 38,151 controls, $7,313(19.2 \%)$ had mothers with influenza-common cold, and these diseases were medically recorded in 2,708 (52.5\%) case mothers and in 3,760 (51.4\%) control mothers. Of 354 cases with IECA, $75(21.2 \%)$ had mother with influenza-common cold, and $40(53.3 \%)$ were medically recorded. However, we were interested only in exposures in the second and/or third gestational month, of 32 pregnant women with influenza-common cold during this

Table 1. Distribution of cases with different groups/types of IECA, their sex ratio and side manifestations

\begin{tabular}{|c|c|c|c|c|c|c|c|c|c|}
\hline \multirow{3}{*}{ Study groups } & \multirow{2}{*}{\multicolumn{2}{|c|}{ Total }} & \multirow{2}{*}{\multicolumn{2}{|c|}{$\begin{array}{c}\text { Sex ratio } \\
\text { (males) }\end{array}$}} & \multicolumn{5}{|c|}{ Side } \\
\hline & & & & & \multicolumn{2}{|c|}{ Unilateral } & \multicolumn{2}{|c|}{ Bilateral } & \multirow{2}{*}{$\begin{array}{c}\text { Unknown } \\
\text { No. }\end{array}$} \\
\hline & No. & $\%$ & No. & $\%$ & No. & $\%$ & No. & $\%$ & \\
\hline Microtia, mild & 74 & 20.9 & 40 & 54.1 & 62 & 96.9 & 2 & 3.1 & 10 \\
\hline Microtia, severe & 236 & 66.7 & 125 & 53.0 & 220 & 97.3 & 6 & 2.7 & 10 \\
\hline Anotia & 24 & 6.8 & 12 & 50.0 & 22 & 91.7 & 2 & 8.3 & 0 \\
\hline Others & 20 & 5.6 & 14 & 70.0 & 7 & 36.8 & 12 & 63.2 & 1 \\
\hline Total & 354 & 100.0 & 191 & 54.0 & 11 & 93.4 & 22 & 6.6 & 21 \\
\hline
\end{tabular}


Table 2. Demographic data of mothers: maternal age and birth order groups with mean maternal age and birth order in the study groups

\begin{tabular}{|c|c|c|c|c|c|c|c|c|c|c|c|}
\hline \multirow[t]{2}{*}{$\begin{array}{l}\text { Demographic } \\
\text { factors }\end{array}$} & \multicolumn{2}{|c|}{$\begin{array}{c}\text { Cases with } \\
\text { IECA } \\
(\mathrm{N}=354)\end{array}$} & \multicolumn{3}{|c|}{$\begin{array}{l}\text { Matched controls } \\
\qquad(\mathrm{N}=511)\end{array}$} & \multicolumn{3}{|c|}{$\begin{array}{l}\text { All controls } \\
(\mathrm{N}=38,151)\end{array}$} & \multicolumn{3}{|c|}{$\begin{array}{l}\text { Malformed controls } \\
\qquad(\mathrm{N}=21,140)\end{array}$} \\
\hline & No. & $\%$ & No & $\%$ & & No. & $\%$ & & No. & $\%$ & \\
\hline \multicolumn{12}{|l|}{ Maternal age } \\
\hline 19 or less & 37 & 10.4 & 50 & 9.8 & \multirow{3}{*}{$\begin{array}{c}\chi^{2}(2)=0.8 \\
p=0.66\end{array}$} & 3,277 & 8.6 & \multirow{3}{*}{$\begin{array}{c}\chi^{2}(2)=2.5 \\
p=0.29\end{array}$} & 2,311 & 10.9 & \multirow{3}{*}{$\begin{array}{c}\chi^{2}(2)=3.9 \\
p=0.14\end{array}$} \\
\hline $20-29$ & 258 & 72.9 & 386 & 75.5 & & 27,602 & 72.3 & & 14,445 & 68.3 & \\
\hline 30 or more & 59 & 16.7 & 75 & 14.7 & & 7,272 & 19.1 & & 4,384 & 20.7 & \\
\hline Mean $\pm S . D$. & \multicolumn{2}{|c|}{$25.2 \pm 5.2$} & \multicolumn{2}{|c|}{$24.9 \pm 4.6$} & $\begin{array}{c}t=0.9 \\
p=0.37\end{array}$ & \multicolumn{2}{|c|}{$25.5 \pm 4.9$} & $\begin{array}{c}t=1.1 \\
p=0.25\end{array}$ & \multicolumn{2}{|c|}{$25.5 \pm 5.3$} & $\begin{array}{c}t=1.1 \\
p=0.29\end{array}$ \\
\hline \multicolumn{12}{|l|}{ Birth order } \\
\hline 1 & 152 & 42.9 & 266 & 52.1 & \multirow{2}{*}{$\begin{array}{l}\chi^{2}(1)=7.0 \\
p=0.008\end{array}$} & 18,209 & 47.7 & \multirow{2}{*}{$\begin{array}{c}\chi^{2}(1)=3.2 \\
p=0.07\end{array}$} & 9,910 & 46.9 & \multirow{2}{*}{$\begin{array}{c}\chi^{2}(1)=2.2 \\
p=0.14\end{array}$} \\
\hline 2 or more & 202 & 57.1 & 245 & 47.9 & & 19,942 & 52.3 & & 11,230 & 53.1 & \\
\hline Mean \pm S.D. & \multicolumn{2}{|c|}{$1.9 \pm 1.0$} & \multicolumn{2}{|c|}{$1.7 \pm 0.9$} & $\begin{array}{c}t=3.1 \\
p=0.002\end{array}$ & \multicolumn{2}{|c|}{$1.7 \pm 0.9$} & $\begin{array}{c}t=4.2 \\
p=<0.0001\end{array}$ & \multicolumn{2}{|c|}{$1.9 \pm 1.1$} & $\begin{array}{l}t=0.0 \\
p=1.00\end{array}$ \\
\hline
\end{tabular}

Table 3. Socio-economic status of mothers: marital and employment status in the study groups

\begin{tabular}{|c|c|c|c|c|c|c|c|c|c|c|c|}
\hline \multirow[t]{2}{*}{$\begin{array}{l}\text { Socio-economic } \\
\text { status }\end{array}$} & \multicolumn{2}{|c|}{$\begin{array}{c}\text { Cases with } \\
\text { IECA } \\
(\mathrm{N}=354)\end{array}$} & \multicolumn{3}{|c|}{$\begin{array}{l}\text { Matched controls } \\
\quad(\mathrm{N}=511)\end{array}$} & \multicolumn{3}{|c|}{$\begin{array}{l}\text { All controls } \\
(\mathrm{N}=38,151)\end{array}$} & \multicolumn{3}{|c|}{$\begin{array}{l}\text { Malformed controls } \\
\qquad(N=21,140)\end{array}$} \\
\hline & No. & $\%$ & No. & $\%$ & OR $(95 \% \mathrm{Cl})$ & No. & $\%$ & $\mathrm{OR}(95 \% \mathrm{Cl})$ & No. & $\%$ & $\mathrm{OR}(95 \% \mathrm{Cl})$ \\
\hline Unmarried & 20 & 5.6 & 11 & 2.2 & $2.9(1.2-6.6)$ & 1,471 & 3.9 & $1.3(0.8-2.1)$ & 1,179 & 5.6 & $1.1(0.7-1.7)$ \\
\hline \multicolumn{12}{|l|}{ Employment } \\
\hline Professional & 20 & 5.6 & 56 & 11.0 & \multirow{7}{*}{$\begin{array}{l}\chi^{2}(6)=24.9 \\
p<0.0001\end{array}$} & 4,353 & 11.4 & \multirow{7}{*}{$\begin{array}{l}\chi^{2}(6)=54.2 \\
p<0.0001\end{array}$} & 1,782 & 8.4 & \multirow{7}{*}{$\begin{array}{l}\chi^{2}(6)=10.0 \\
p<0.0001\end{array}$} \\
\hline Managerial & 76 & 21.5 & 136 & 26.6 & & 10,134 & 26.6 & & 4,593 & 21.7 & \\
\hline Skilled worker & 100 & 28.2 & 149 & 29.2 & & 11,690 & 30.6 & & 5,880 & 27.8 & \\
\hline Semiskilled worker & 65 & 18.4 & 80 & 15.7 & & 5,783 & 15.2 & & 3.564 & 16.9 & \\
\hline Unskilled worker & 22 & 6.2 & 21 & 4.1 & & 1,859 & 4.9 & & 1,394 & 6.6 & \\
\hline Housewife & 45 & 12.7 & 28 & 5.5 & & 2,038 & 5.3 & & 1,944 & 9.2 & \\
\hline Others & 26 & 7.3 & 41 & 8.0 & & 2,294 & 6.0 & & 1,983 & 9.4 & \\
\hline
\end{tabular}

time window, 21 (65.6\%) had medically recorded disease. If only medically recorded influenza-common cold in the second and/ or third gestational months of pregnant women was evaluated, a higher OR with $95 \%$ CI of IECA was found at the comparison of mothers of cases with matched controls $(4.9,1.4-9.3)$, all controls $(2.9,1.3-4.8)$ and malformed controls $(2.0,1.1-4.2)$.

In the next step antifever drugs (acetylsalicylic acid, paracetamol) and antibiotics (ampicillin, penamecillin, parenteral benzylpenicillin), used for the treatment of influenza-common cold, were evaluated. These drugs had no association with the higher risk of IECA after their use during the entire pregnancy or in the second and/or third gestational months. However, of 32 pregnant women with influenza-common cold during the critical period of IECA, only $8(25.0 \%)$ were treated with antifever drugs while of their 13 matched controls, $11(84.6 \%)$, thus this treatment may prevent high fever related IECA.

The data of cases with IECA born to mothers with otitis media are summarised in Table 5 . The mothers of these 4 cases had prospectively and medically recorded acute otitis media in the prenatal maternity logbook. Of these 4 cases, all belonged to the CA-group of "Others" and 3 were examined personally. In addition, maternal otitis media occurred in the second and/ or third gestational months of gestation, i.e. the critical period of IECA in 3 cases. The mothers of these cases were late or not appropriately treated.

The prevalence of chronic maternal diseases is shown in different study groups in Table 6. There was no higher risk of IECA in any disease.

\section{DISCUSSION}

The major findings of the study showed an association of frequent high fever related maternal influenza-common cold with secondary consequences and rare otitis media with the higher risk of IECA. 
Table 4. Incidence of acute disease groups during the study pregnancy in the mothers of study groups

\begin{tabular}{|c|c|c|c|c|c|c|c|c|c|c|c|c|c|c|}
\hline \multirow[t]{2}{*}{$\begin{array}{l}\text { Acute disease } \\
\text { groups }\end{array}$} & \multicolumn{2}{|c|}{$\begin{array}{c}\text { Cases with } \\
\text { IECA } \\
(\mathrm{N}=354)\end{array}$} & \multicolumn{4}{|c|}{$\begin{array}{l}\text { Matched controls } \\
\qquad(\mathrm{N}=511)\end{array}$} & \multicolumn{4}{|c|}{$\begin{array}{l}\text { All controls } \\
(\mathrm{N}=38,151)\end{array}$} & \multicolumn{4}{|c|}{$\begin{array}{l}\text { Malformed controls } \\
\qquad(\mathrm{N}=21,140)\end{array}$} \\
\hline & No. & $\%$ & No. & $\%$ & OR & $95 \% \mathrm{Cl}$ & No. & $\%$ & OR & $95 \% \mathrm{Cl}$ & No. & $\%$ & OR & $95 \% \mathrm{Cl}$ \\
\hline $\begin{array}{l}\text { Influenza-common } \\
\text { cold }\end{array}$ & 75 & 21.2 & 79 & 15.5 & 1.6 & $1.1-2.3$ & 7,013 & 18.4 & 1.3 & $0.9-1.6$ & 4,469 & 21.1 & 1.0 & $0.8-1.3$ \\
\hline Respiratory system & 43 & 12.1 & 54 & 10.6 & 1.3 & $0.9-2.1$ & 3,452 & 9.0 & 1.5 & $1.1-2.0$ & 1,916 & 9.1 & 1.4 & $1.0-1.9$ \\
\hline Digestive system & 2 & 0.6 & 4 & 0.8 & 0.8 & $0.1-4.4$ & 232 & 0.6 & 1.0 & $0.2-4.1$ & 203 & 1.0 & 0.6 & $0.1-2.4$ \\
\hline Urinary tract & 32 & 9.0 & 30 & 5.9 & 1.7 & $0.9-2.9$ & 2,299 & 6.0 & 1.5 & $1.1-2.2$ & 1,454 & 6.9 & 1.3 & $0.9-1.9$ \\
\hline Genital organs & 19 & 5.4 & 38 & 7.4 & 0.5 & $0.3-1.1$ & 2,856 & 7.5 & 0.7 & $0.4-1.1$ & 1,504 & 7.1 & 0.7 & $0.5-1.2$ \\
\hline Other & 14 & 4.0 & 10 & 2.0 & 2.1 & $0.9-4.8$ & 981 & 2.6 & 1.7 & $0.9-2.9$ & 722 & 3.4 & 1.2 & $0.7-2.0$ \\
\hline Orofacial herpes & 5 & 1.4 & 5 & 1.0 & 1.4 & $0.4-4.9$ & 571 & 1.5 & 1.1 & $0.4-2.6$ & 386 & 1.8 & 0.8 & $0.3-1.9$ \\
\hline Otitis media & 4 & 1.1 & 1 & 0.2 & 5.2 & $1.6-28.3$ & 55 & 0.1 & 8.1 & $2.9-22.5$ & 52 & 0.2 & 4.6 & $1.7-12.9$ \\
\hline Rest & $5^{*}$ & 1.4 & 4 & 0.8 & 3.7 & $0.7-20.3$ & 355 & 0.9 & 1.5 & $0.6-3.7$ & 284 & 1.3 & 1.1 & $0.4-2.6$ \\
\hline $\begin{array}{l}\text { Influenza-common } \\
\text { cold } \\
\text { II-III month }\end{array}$ & 32 & 9.0 & 13 & 2.5 & 4.3 & $1.9-7.4$ & 1,515 & 4.0 & 2.4 & $1.5-3.6$ & 1,099 & 5.2 & 1.8 & $1.2-2.2$ \\
\hline $\begin{array}{l}\text { Respiratory system } \\
\text { II-III month }\end{array}$ & 15 & 4.2 & 17 & 3.3 & 1.3 & $0.4-2.4$ & 1,259 & 3.3 & 1.3 & $0.7-2.6$ & 871 & 4.1 & 1.0 & $0.6-2.0$ \\
\hline $\begin{array}{l}\text { Urinary tract } \\
\text { II-III month }\end{array}$ & 4 & 1.1 & 5 & 1.0 & 1.1 & $0.2-2.4$ & 472 & 1.2 & 0.9 & $0.3-2.0$ & 292 & 1.4 & 0.8 & $0.3-2.6$ \\
\hline
\end{tabular}

*toxoplasmosis 2, chickenpox 1, cytomegalic infection 1, acute tuberculosis 1

OR adjusted for maternal age and employment status, birth order and related drug treatments

Bold numbers show significant associations

Table 5. Data of cases with IECA in the children of mothers with acute otitis media during the study pregnancy

\begin{tabular}{|l|c|c|l|c|c|c|}
\hline Sex & $\begin{array}{c}\text { Gestational } \\
\text { age (wk) }\end{array}$ & $\begin{array}{c}\text { Birth weight } \\
\text { (g) }\end{array}$ & \multicolumn{1}{|c|}{ IECA } & $\begin{array}{c}\text { Otitis media } \\
\text { (gestational } \\
\text { month) }\end{array}$ & $\begin{array}{c}\text { Other diseases } \\
\text { (month) }\end{array}$ & $\begin{array}{c}\text { Drug treatment } \\
\text { (month) }\end{array}$ \\
\hline Male & 38 & 3,350 & $\begin{array}{l}\text { Atresia of auditory canal with fusion } \\
\text { of ear ossicles and anotia }\end{array}$ & II-III & - & - \\
\hline Male & 38 & 2,900 & $\begin{array}{l}\text { Atresia of auditory canal with fusion } \\
\text { of ear ossicles and severe microtia }\end{array}$ & III-IV & $\begin{array}{c}\text { Pre-eclampsia } \\
\text { (V-VIII) }\end{array}$ & $\begin{array}{c}\text { Dipyrone } \\
\text { (III-IV) }\end{array}$ \\
\hline Female & 41 & 3,550 & $\begin{array}{l}\text { absent of membranous labyrinth } \\
\text { and organ Cortilitis and anotia }\end{array}$ & $\begin{array}{c}\text { Xylometazoline } \\
\text { (IV-VI) } \\
\text { Penamecillin } \\
\text { (IV-VI) }\end{array}$ \\
\hline Male & 39 & 3,850 & $\begin{array}{l}\text { Atresia of auditory canal with fusion } \\
\text { of ear ossicles and severe microtia }\end{array}$ & VI-VII & $\begin{array}{c}\text { Tonsillitis } \\
\text { (V-VI) }\end{array}$ & $\begin{array}{c}\text { Xylometazoline } \\
\text { (VI-VII) }\end{array}$ \\
\hline
\end{tabular}

The secondary findings of the study indicates a higher mean birth order and lower socio-economic status of mothers of cases with IECA compared to the mothers of controls, though these associations do not seem to be characteristic only IECA because similar data were found in malformed controls. Chronic diseases and drug treatments did not show association with the higher risk of IECA.

High fever related maternal influenza (20), common cold with secondary complications (21) and acute tonsillitis (22) associated with a higher risk of some CAs due to the teratogenic effect of high fever defined $>38.5^{\circ} \mathrm{C}$ (23) in previous studies. Cases with IECA were not among these CA-groups, because CAs of ears were evaluated together. However, the previously delineated spectrum of hyperthermia-induced CAs $(24)$ or CA-syndrome $(25,26)$ included CAs of external ears as well, and this study confirmed that IECA including microtia/anotia is part of hyperthermia-induced CA-spectrum/syndrome.

In general high fever related maternal disorders are treated by drugs, thus related drugs treatments can be considered at the explanation of higher risk of IECA. However, the teratogenic potential of antifever drugs such as acetylsalicylic acid $(27,28)$, paracetamol (29) and antimicrobial ampicillin (30), penamecillin (31), parenteral benzylpenicillin (32) was evaluated and these drugs did not associate with the higher risk of IECA in the previous 
Table 6. Prevalence of chronic diseases in the mothers of cases with IECA, matched controls, all controls and malformed controls

\begin{tabular}{|c|c|c|c|c|c|c|c|c|c|c|c|c|c|c|}
\hline \multirow[t]{2}{*}{ Chronic diseases } & \multicolumn{2}{|c|}{$\begin{array}{c}\text { Cases with } \\
\text { IECA } \\
(\mathrm{N}=354)\end{array}$} & \multicolumn{4}{|c|}{$\begin{array}{l}\text { Matched controls } \\
\qquad(\mathrm{N}=511)\end{array}$} & \multicolumn{4}{|c|}{$\begin{array}{l}\text { All controls } \\
(\mathrm{N}=38,151)\end{array}$} & \multicolumn{4}{|c|}{$\begin{array}{l}\text { Malformed controls } \\
\qquad(\mathrm{N}=21,140)\end{array}$} \\
\hline & No. & $\%$ & No. & $\%$ & OR & $95 \% \mathrm{Cl}$ & No. & $\%$ & OR & $95 \% \mathrm{Cl}$ & No. & $\%$ & OR & $95 \% \mathrm{Cl}$ \\
\hline Diabetes mellitus & 3 & 0.8 & 3 & 0.6 & 2.4 & $0.1-39.1$ & 229 & 0.6 & 1.5 & $0.5-4.7$ & 140 & 0.7 & 1.3 & $0.4-4.2$ \\
\hline Epilepsy & 1 & 0.3 & 0 & 0.0 & - & - & 90 & 0.2 & 1.1 & $0.2-7.9$ & 89 & 0.4 & 0.7 & $0.1-4.8$ \\
\hline Migraine & 6 & 1.7 & 6 & 1.2 & 1.8 & $0.6-5.9$ & 708 & 1.9 & 0.9 & $0.4-2.1$ & 511 & 2.4 & 0.7 & $0.3-1.6$ \\
\hline $\begin{array}{l}\text { Essential } \\
\text { hypertension }\end{array}$ & 20 & 5.6 & 36 & 7.0 & 0.9 & $0.5-1.6$ & 2,692 & 7.1 & 0.8 & $0.5-1.3$ & 1,484 & 7.0 & 0.8 & $0.5-1.3$ \\
\hline $\begin{array}{l}\text { Hypotension, } \\
\text { primary }\end{array}$ & 13 & 3.7 & 17 & 3.3 & 1.1 & $0.5-2.3$ & 1,265 & 3.3 & 1.1 & $0.6-1.9$ & 504 & 2.4 & 1.6 & $0.9-2.7$ \\
\hline $\begin{array}{l}\text { Phlebitis/throm- } \\
\text { bophlebitis }\end{array}$ & 6 & 1.7 & 7 & 1.4 & 1.3 & $0.4-3.9$ & 975 & 2.6 & 0.7 & $0.3-1.5$ & 317 & 1.5 & 1.1 & $0.5-2.5$ \\
\hline $\begin{array}{l}\text { Varicose veins in } \\
\text { lower extremities }\end{array}$ & 9 & 2.5 & 7 & 1.4 & 2.0 & $0.7-5.8$ & 566 & 1.5 & 1.7 & $0.9-3.4$ & 297 & 1.4 & 1.8 & $0.9-3.6$ \\
\hline Hemorrhoids & 14 & 4.0 & 28 & 5.5 & 0.6 & $0.3-1.3$ & 1,624 & 4.3 & 1.0 & $0.6-1.6$ & 742 & 3.5 & 1.1 & $0.7-1.9$ \\
\hline Constipation & 6 & 1.7 & 20 & 3.9 & 0.4 & $0.2-1.0$ & 799 & 2.1 & 0.9 & $0.4-2.0$ & 430 & 2.0 & 0.9 & $0.4-2.0$ \\
\hline Other & 21 & 5.9 & 34 & 6.7 & 1.0 & $0.5-1.8$ & 2,594 & 6.8 & 0.9 & $0.6-1.4$ & 1,512 & 7.2 & 0.8 & $0.5-1.3$ \\
\hline
\end{tabular}

OR adjusted for maternal age and employment status, birth order and related drug treatments

studies and in this dataset. Thus, the possible association of high fever related influenza-common cold with higher risk of IECA cannot be explained by the related drug treatment.

The major message of our study is that the frequent high fever related influenza-common cold may associate with a higher risk of IECA, but as our previous studies showed, the high fever related risk of CAs can be prevented by antifever drugs (23). Thus, it is reasonable to suppose that high fever related IECA also preventable by appropriate antifever therapy, and paracetamol/acetaminophen group may be the first choice in antifever treatment.

In addition, a higher risk of complex ear CAs including middle ear CA with severe anotia/microtia was found in 4 cases of mothers with otitis media, and this association was supported by three factors: (i) there was an overlap between the critical period of IECA and the exposure, i.e. otitis media in 3 cases. (ii) these CAs of ear were similar including severe defects of external ear/ auditory canal and middle ear. (iii) Other possible external factors that could explain this association were not found. Thus, this finding confirmed the results of a previous study (33).

The strength of our study is the population-based data set of the HCAR and HCCSCA in an ethnically homogeneous Hungarian (Caucasian) population. Additional strength is that the diagnoses of ear CA were based on the report of medical doctors and checked in the HCAR and later modified, if necessary, in the HCCSCA. In addition, one-third of cases were examined personally by the principal investigator of the project. The available prenatal maternity logbooks helped to evaluate separately only prospectively and medically recorded maternal diseases. Finally the use of matched and malformed controls helped us to diminish the recall bias regarding maternal self-reported information (34) and the effect of confounders.

However, this dataset also has limitations. High fever was not documented in all pregnant women affected with influenzacommon cold, because only their subgroup was visited at home or examined in our institution or their homes and to obtain the necessary data through personal interview and available medical records. About $92 \%$ of pregnant women with influenza reported high fever (20), while $57 \%$ of pregnant women who had common cold with secondary complications had high fever (21). In general this high fever was confirmed with the parallel use of antifever drugs. Nevertheless, the high fever was extrapolated from the above subgroup for the major part of pregnant women, but these figures showed good agreement with the real figures in our validation study (12).

In conclusion, the mothers of cases with IECA had a higher incidence of high fever related influenza/common cold with secondary complications during the critical period of IECA. A higher risk of IECA was also found in the mothers with otitis media but this association was based on 4 cases only.

\section{Acknowledgement}

Authors thank Erzsébet H. Puhó for her help in the statistical analysis of data.

\section{REFERENCES}

1. Opitz JM. The developmental field concept in clinical genetics. J Pediatr. 1982 Nov;101(5):805-9.

2. Carey JC, Park SAH, Muntz HR. External ear. In: Stevenson ED, Hall JG, Goodman RM, editors. Human malformations and related anomalies. 2nd ed. New York: Oxford University Press; 2006. p. 329-35.

3. Kountakis SE, Helidonis E, Jahrsdoerfer RA. Microtia grade as an indicator of middle ear development in aural atresia. Arch Otolaryngol Head Neck Surg. 1995 Aug;121(8):885-6.

4. Aase JM, Tegtmeier RE. Microtia in New Mexico: evidence for multifactorial causation. Birth Defects Orig Artic Ser. 1977;13(3A):113-6.

5. Mastroiacovo P, Corchia C, Botto LD, Lanni R, Zampino G, Fusco D. Epidemiology and genetics of microtia-anotia: a registry based study on over one million births. J Med Genet. 1995 Jun;32(6):453-7. 
6. Suutarla S, Rautio J, Ritvanen A, Ala-Mello S, Jero J, Klockars T. Microtia in Finland: comparison of characteristics in different populations. Int J Pediatr Otorhinolaryngol. 2007 Aug;71(8):1211-7.

7. Czeizel AE, Rockenbauer M, Siffel C, Varga E. Description and mission evaluation of the Hungarian case-control surveillance of congenital abnormalities, 1980-1996. Teratology. 2001 May;63(5):176-85.

8. Czeizel AE. First 25 years of the Hungarian congenital abnormality registry. Teratology. 1997 May;55(5):299-305.

9. Czeizel AE, Telegdi L, Tusnády G. Multiple congenital abnormalities. Budapest: Akadémiai Kiadó; 1988.

10. Czeizel AE, Intôdy Z, Modell B. What proportion of congenital abnormalities can be prevented? BMJ. 1993 Feb 20;306(6876):499-503. Erratum in: BMJ. 1993 Mar 20;306(6880):771.

11. Czeizel AE, Petik D, Puho E. Smoking and alcohol drinking during pregnancy. The reliability of retrospective maternal self-reported information. Cent Eur J Public Health. 2004 Dec;12(4):179-83.

12. Czeizel AE, Petik D, Vargha P. Validation studies of drug exposures in pregnant women. Pharmacoepidemiol Drug Saf. 2003 JulAug;12(5):409-16.

13. Czeizel AE, Vargha P. Periconceptional folic acid/multivitamin supplementation and twin pregnancy. Am J Obstet Gynecol. 2004 Sep;191(3):790-4.

14. Marx H. Deformities of the ear. In: Denker A, Kahler O, editors. Handbook of Otorhinolaryngology Including Bordering Disciplines. Berlin: J. Springer; 1926. p. 131-69.

15. Meurman Y. Congenital microtia and meatal atresia; observations and aspects of treatment. AMA Arch Otolaryngol. 1957 Oct;66(4):443-63.

16. Tasse C, Böhringer S, Fischer S, Lüdecke HJ, Albrecht B, Horn D, et al. Oculo-auriculo-vertebral spectrum (OAVS): clinical evaluation and severity scoring of 53 patients and proposal for a new classification. Eur J Med Genet. 2005 Oct-Dec;48(4):397-411.

17. Poswillo D. The pathogenesis of the first and second branchial arch syndrome. Oral Surg Oral Med Oral Pathol. 1973 Mar;35(3):302-28.

18. Puhó E, Métneki J, Czeizel AE. Maternal employment status and isolated orofacial clefts in Hungary. Cent Eur J Public Health. 2005 Sep;13(3):144-

19. Czeizel AE. Periconceptional folic acid and multivitamin supplementation for the prevention of neural tube defects and other congenital abnormalities. Birth Defects Res A Clin Mol Teratol. 2009 Apr;85(4):260-8.

20. Acs N, Bánhidy F, Puhó E, Czeizel AE. Maternal influenza during pregnancy and risk of congenital abnormalities in offspring. Birth Defects Res A Clin Mol Teratol. 2005 Dec;73(12):989-96.

21. Ács N, Bánhidy F, Puhó E, Czeizel AE. Population-based case-control study of common cold during pregnancy and congenital abnormalities. Eur J Epidemiol. 2006;21(1):65-75.

22. Acs N, Bánhidy F, Puhó EH, Czeizel AE. Acute respiratory infections during pregnancy and congenital abnormalities: a population-based casecontrol study. Congenit Anom (Kyoto). 2006 Jun;46(2):86-96.
23. Czeizel AE, Ács N, Bánhidy F, Puho HE, Vogt G. Primary prevention of congenital abnormalities due to high fever related maternal diseases by antifever therapy and folic acid supplementation. Curr Women's Health Rev. 2007;3(3):190-201.

24. Jones KL. Hyperthermia-induced spectrum of defects. In: Jones KL. Smith's recognizable patterns of human malformation. 4th ed. Philadelphia: WB Saunders Co; 2004. p. 516-9.

25. Czeizel AE, Puhó EH, Acs N, Bánhidy F. High fever-related maternal diseases as possible causes of multiple congenital abnormalities: a population-based case-control study. Birth Defects Res A Clin Mol Teratol. 2007 Jul;79(7):544-51.

26. Czeizel AE, Puhó EH, Acs N, Bánhidy F. Delineation of a multiple congenital abnormality syndrome in the offspring of pregnant women affected with high fever-related disorders: a population-based study. Congenit Anom (Kyoto). 2008 Dec;48(4):158-66.

27. Czeizel AE, Rockenbauer M, Mosonyi A. A population-based case-contro teratologic study of acetylsalicylic acid treatments during pregnancy. Pharmacoepidemiol Drug Saf. 2000 May;9(3):193-205.

28. Nørgård B, Puhó E, Czeizel AE, Skriver MV, Sørensen HT. Aspirin use during early pregnancy and the risk of congenital abnormalities: a population-based case-control study. Am J Obstet Gynecol. 2005 Mar;192(3):922-3.

29. Rebordosa C, Kogevinas M, Horváth-Puhó E, Nørgård B, Morales M, Czeizel AE, et al. Acetaminophen use during pregnancy: effects on risk for congenital abnormalities. Am J Obstet Gynecol. 2008 Feb;198(2):178. e1-7.

30. Czeizel AE, Rockenbauer M, Sørensen HT, Olsen J. A population-based case-control teratologic study of ampicillin treatment during pregnancy. Am J Obstet Gynecol. 2001 Jul;185(1):140-7.

31. Czeizel AE, Rockenbauer M, Sorensen HT, Olsen J. The safety of penicillin V: oral penamecillin use during pregnancy the importance and limitation of recall bias. Congenit Anom. 1999;39(4):267-79.

32. Czeizel AE, Rockenbauer M, Sorensen HT, Olsen J. A population-based case-control teratological study of three parenteral penicillins G. Congenit Anom. 1999;39(3):117-26.

33. Acs N, Bánhidy F, Puhó EH, Czeizel AE. A possible association between maternal otitis media and ear defect in their offspring. Am J Otolaryngol. 2011 May-Jun;32(3):203-9.

34. Czeizel AE. The estimation of human teratogenic/fetotoxic risk of exposures to drugs on the basis of Hungarian experience: a critical evaluation of clinical and epidemiological models of human teratology. Expert Opin Drug Saf. 2009 May;8(3):283-303

Received March 2, 2011 Accepted in revised form July 1, 2011 